\title{
Is poor pregnancy outcome a risk factor in rheumatoid arthritis?
}

Tim D Spector, Alan J Silman

\begin{abstract}
Previous work has suggested that prior poor reproductive outcome may be a risk factor in rheumatoid arthritis (RA). A case-control study of 195 women with RA and 462 control women from two different sources is presented here. No increase in rates of spontaneous abortion was seen in the women with $\mathbf{R A}$; indeed a protective effect was seen with an age adjusted odds ratio of 0.6 (95\% confidence interval (CI) 0.4 to 0.9 ). A nonsignificant increase in stillbirth rates was seen in women with RA, producing an age adjusted odds ratio of $1.5(95 \%$ CI 0.7 to 3.4$)$. No differences in rates of induced abortion were seen. Thus although hormonal and gynaecological factors are undoubtedly important in the aetiology of RA, it was not possible to confirm that prior poor reproductive outcome is a risk factor in $\mathbf{R A}$.
\end{abstract}

Rheumatoid arthritis (RA) is a disease of unknown aetiology, characterised by a $3: 1$ female to male sex ratio. ${ }^{1}$ The disease commonly remits during pregnancy and relapses after delivery ${ }^{2}$ and alters during the menstrual cycle. ${ }^{3}$ Pregnancy itself may be a risk factor for $\mathrm{RA},{ }^{4}$ though population based epidemiological studies have produced conflicting results. ${ }^{5}$ An extension of this hypothesis is that poor reproductive outcome is a predictor of future risk. ${ }^{6} \mathrm{~A}$ small case-control study comparing women with RA with their unaffected female relatives showed an increased rate of stillbirth before disease onset in the former ${ }^{7}$ whereas a study of a mainly urban black population in the United States showed an increase in spontaneous abortion. ${ }^{8}$ We therefore undertook a casecontrol study of obstetric factors in women with RA using two different comparison groups to explore further whether poor reproductive outcome before the development of RA was a risk factor for the disease.

\footnotetext{
Departments of

Rheumatology and Epidemiology St Bartholomew's Hospital, London T D Spector

ARC Epidemiology Unit, Manchester A J Silman

Correspondence to: Dr T D Spector, Department of Rheumatology, St Bartholomew's Hospital, London ECIA 7BE.

Accepted for publication 3 April 1989
}

\section{Patients and methods}

The patients comprised women aged 35-70 with ciation criteria) currently attending one of six rheumatology centres in East London. The controls who were within the same age range were (a) women with a clinical diagnosis of osteoarthritis (OA) attending the same clinics; $(b)$ women randomly selected from electoral registers in Greater London.

Information on obstetric and gynaecological history was obtained by means of a postal questionnaire which had been validated with interdefinite RA (1958 American Rheumatism Asso- view as part of a previous study ${ }^{7}$ and with obstetric records by other authors. ${ }^{9}$ Details were obtained of year of birth, marital status, menarche, menopause, spontaneous and induced abortions, dates and outcomes of each pregnancy, and for the hospital (arthritis) groups, age of disease onset. For the hospital groups the diagnosis and dates of disease onset were validated wherever possible with the clinical records by the authors.

After a second reminder letter usable replies were received from 260 women with $\mathrm{RA}$ with a response rate of $89 \%, 292$ women with OA $(85 \%)$, and 267 women from the electoral register $(71 \%$ approx). (The numbers of nonresponders in the age range could not be calculated exactly, and this figure is an estimate.) This analysis was restricted to those women reporting at least one pregnancy. Further, as the aim was to investigate reproductive loss before disease onset, women in the RA and OA groups whose reported disease onset was before their last pregnancy were also excluded $(n=22)$. This left 195 women with RA, 233 with OA, and 229 population controls for further analysis. As an additional comparison group, replies were used from a similar questionnaire which had been sent to 708 women aged 35 to 65 from a local general practice as part of another study. The response rate from this group was $72 \%$ (508 women).

\section{ANALYSIS}

The rates of reproductive loss were expressed both as a percentage of the total number of pregnancies and as the percentage of women experiencing at least one poor reproductive event. Crude odds ratios and the $95 \%$ confidence intervals were calculated for stillbirths and spontaneous and induced abortions. Differences in age were accounted for by using the stratified analysis method of Mantel-Haenszel.

\section{Results}

Table 1 gives the baseline characteristics for the four groups. The mean age in the groups ranged from 52 to 58 years, the population control groups being approximately five years younger than the arthritis groups. The mean ages of first symptoms were 46.4 (SD 9.9) and 46.2 (11.2) years and of first referral $48 \cdot 6(10 \cdot 1)$ and $51 \cdot 3$ (9.7) years for the $\mathrm{RA}$ and $\mathrm{OA}$ groups respectively.

The effect of pregnancy outcome was studied for each individual. In the three groups 1840 pregnancies were available for analysis (table 
Table 1: Baseline characteristics

\begin{tabular}{llll}
\hline Characteristic & $\begin{array}{l}R A^{*} \\
(n=195)\end{array}$ & $\begin{array}{l}O A^{*} \\
(n=233)\end{array}$ & $\begin{array}{l}E R^{*} \\
(n=229)\end{array}$ \\
\hline $\begin{array}{l}\text { Mean age (SD) } \\
\text { Number unmarried }\end{array}$ & $\begin{array}{c}57 \cdot 7(7 \cdot 6) \\
\quad 3(2)\end{array}$ & $\begin{array}{l}57 \cdot 2(9 \cdot 0) \\
8(3)\end{array}$ & $\begin{array}{l}52 \cdot 7(10 \cdot 2) \\
13(6)\end{array}$ \\
$\begin{array}{l}\text { Mean age first } \\
\text { symptoms (SD) }\end{array}$ & $46 \cdot 4(9 \cdot 9)$ & $46 \cdot 2(11 \cdot 2)$ & - \\
$\begin{array}{c}\text { Mean age first } \\
\text { referral (SD) }\end{array}$ & $48 \cdot 6(10 \cdot 1)$ & $51 \cdot 3(9 \cdot 7)$ & - \\
\hline
\end{tabular}

${ }^{*} \mathrm{RA}=$ rheumatoid arthritis; $\mathrm{OA}=$ osteoarthritis; $\mathrm{ER}=$ electora register.

2). Pregnancies ending as ectopic pregnancies were treated as spontaneous abortions for the analysis. Subgroup analysis by birth order and maternal age did not explain any differences in pregnancy outcome between the three groups of women, and the analysis presented is therefore based on all pregnancies regardless of maternal age or birth order.

The number of live births per woman was similar in the three groups (range $2 \cdot 3$ to $2 \cdot 4$ ). No increase in spontaneous or induced abortions or postnatal deaths was noted in the RA group compared with the controls. Indeed the women with RA had lower rates of spontaneous abortions than the other groups, implying a protective effect with an age adjusted odds ratio for RA $v$ all controls of 0.6 (95\% CI 0.4 to 0.9$)$. There was a slightly higher rate of stillbirths among the women with RA, but this failed to reach statistical significance. (Age adjusted odds ratio for RA $v$ all controls of $1.5(95 \% \mathrm{CI} 0.7$ to 3.4).) Table 3 gives in full the crude and age adjusted odds ratios for RA $v$ control groups.

Further strengthening of these findings comes from the extra comparison group from the local general practice. Of the 508 women who replied, 1053 pregnancies were reported. Of these women, $112(26.5 \%)$ had experienced at least one spontaneous abortion and $16(3.8 \%)$ reported a stillbirth. These rates corresponded closely with those from the other comparison groups, and inclusion of these figures did not alter the conclusions. The rate of multiple birth was similar in the three groups: eight twin pairs in RA $(4 \cdot 1 \%$ of women), 10 in $\mathrm{OA}(4 \cdot 3 \%)$, and eight in the population $(3.5 \%)$, and no differences were found in birth weights or sex ratios of children.

\section{Discussion}

These data do not support our earlier hypothesis that women with RA have an increased rate of spontaneous abortions or stillbirths before the onset of the disease. The figures for miscarriages in the control groups fall within the recalled figures for pregnancies ending in clinical miscarriage in the United Kingdom, ${ }^{10}$ and thus appear representative of the population. The similarity in rates between the population control groups also supports this. The rates for stillbirth were marginally higher in the RA group, though not significantly so. This study was of sufficient size to have an $80 \%$ power to detect a doubling in stillbirth rate. Women's recall of pregnancies and miscarriages has been found to be accurate, ${ }^{9}$ though small differences between responders and non-responders have been found in some studies, ${ }^{11}$ while others have found no differences. ${ }^{12}$

So although the possibility of a small effect of stillbirth cannot be excluded, as the rate of stillbirth in the population is low the number of

Table 2: Reproductive outcomes

\begin{tabular}{|c|c|c|c|}
\hline & $R A^{*}(\mathrm{n}=195)$ & $\mathrm{OA}^{*}(\mathrm{n}=233)$ & $\mathrm{ER}^{*}(\mathrm{n}=229)$ \\
\hline Total pregnancies & 519 & 679 & 642 \\
\hline \multicolumn{4}{|l|}{$\begin{array}{l}\text { Outcomes } \\
\text { Live births (alive at } 12 \text { months) (mean }\end{array}$} \\
\hline $\begin{array}{l}\text { number/woman) } \\
\text { Spontaneous abortions }\end{array}$ & $457(2 \cdot 3)$ & $545(2 \cdot 3)$ & $547(2 \cdot 4)$ \\
\hline $\begin{array}{l}\text { Number (\% of total pregnancies) } \\
\text { Number of women (\%) }\end{array}$ & $\begin{array}{l}34(6 \cdot 5) \\
28(14 \cdot 3)\end{array}$ & $\begin{array}{l}95(14 \cdot 0) \\
64(27 \cdot 5)\end{array}$ & $\begin{array}{l}59(9 \cdot 2) \\
44(19 \cdot 2)\end{array}$ \\
\hline Induced abortions & & & \\
\hline $\begin{array}{l}\text { Number (\% of total pregnancies) } \\
\text { Number of women }(\%)\end{array}$ & $\begin{array}{l}15(2 \cdot 9) \\
13(6 \cdot 7)\end{array}$ & $\begin{array}{l}19(2 \cdot 8) \\
12(5 \cdot 1)\end{array}$ & $\begin{array}{l}16(2 \cdot 5) \\
14(6 \cdot 1)\end{array}$ \\
\hline Stillbirths & & & \\
\hline $\begin{array}{l}\text { Number (\% total livebirths) } \\
\text { Number of women (\%) } \\
\text { Infant deaths }\end{array}$ & $\begin{array}{r}10(2 \cdot 2) \\
9(4 \cdot 6)\end{array}$ & $\begin{array}{l}10(1 \cdot 8) \\
10(4 \cdot 3)\end{array}$ & $\begin{array}{l}7(1 \cdot 3) \\
7(3 \cdot 0)\end{array}$ \\
\hline $\begin{array}{l}\text { Number (\% of total pregnancies) } \\
\text { Number of women (\%) }\end{array}$ & $\begin{array}{l}3(0 \cdot 6) \\
3(1 \cdot 5)\end{array}$ & $\begin{array}{r}10(1 \cdot 5) \\
7(3 \cdot 0)\end{array}$ & $\begin{array}{l}13(2 \cdot 0) \\
12(5 \cdot 2)\end{array}$ \\
\hline
\end{tabular}

${ }^{*} \mathrm{RA}=$ rheumatoid arthritis; $\mathrm{OA}=$ osteoarthritis; $\mathrm{ER}=$ electoral register.

Table 3: Relative risks: crude and age adjusted odds ratio

\begin{tabular}{llll}
\hline & $R A^{*} v \mathrm{OA}^{*}$ & RA $v \mathrm{ER}^{*}$ & $\mathrm{RA} v$ Both \\
\hline $\begin{array}{l}\text { Stillbirths } \\
\text { Crude OR* (95\% CI*) }\end{array}$ & $1.1(0.4$ to 2.7$)$ & $1.4(0.4$ to 4.6$)$ & $1.5(0.7$ to 3.4$)$ \\
Rmh* (95\% CI) & $1.0(0.4$ to 2.6$)$ & $1.8(0.5$ to 6.9$)$ & $1.5(0.7$ to 3.4$)$ \\
Spontaneous abortions & & & \\
Crude OR (95\% CI) & $0.4(0.3$ to 0.7$)$ & $0.7(0.4$ to 1.2$)$ & $0.55(0.3$ to 0.7$)$ \\
Rmh (95\% CI) & $0.4(0.3$ to 0.7$)$ & $0.9(0.5$ to 1.6$)$ & $0.6(0.4$ to 0.9$)$ \\
Induced abortions & & $1.1(0.5$ to 2.4$)$ & $1.2(0.6$ to 2.4$)$ \\
Crude OR (95\% CI) & $1.3(0.6$ to 2.9$)$ & $2.7(1.0$ to 7.1$)$ & $1.7(0.8$ to 3.4$)$ \\
Rmh (95\% CI) & $1.4(0.6$ to 3.0$)$ & & \\
\hline
\end{tabular}

* RA=rheumatoid arthritis; $\mathrm{OA}=$ osteoarthritis; $\mathrm{ER}=$ electoral register; $\mathrm{OR}=$ odds ratio; $\mathrm{CI}=$ confidence interval; $\mathrm{Rmh}=\mathrm{Mantel}$ Haenszel adjusted odds ratio. 
cases of RA being attributable to stillbirths will be small (estimated population attributable risk is $2 \cdot 2 \%$ ).

Studies on the effect of reproductive outcome have previously been performed. The study of Kay and Bach of 209 women with RA looked at miscarriage rates and found no differences compared with general practice controls. ${ }^{13}$ A study by Kaplan of 96 women with RA found a $50 \%$ increase in rates of miscarriage but not induced abortions compared with 113 controls with OA. ${ }^{8}$ The discrepancies of this study and our own are difficult to explain, but the most striking difference between the study populations was the racial characteristics-in Kaplan's study only $16 \%$ of the women were white. Although in our study the women were not systematically categorised into racial groups, an estimated $95 \%$ were white, suggesting that the results of the former study may not be easily extrapolated to white populations. The other point is that our study was considerably larger, having an $80 \%$ power to detect an odds ratio of 1.5 for miscarriage rates.

The results from this study for stillbirths are at variance with our recently reported observations, using the same methodology, showing a markedly increased perinatal loss in women with RA. ${ }^{7}$ The patients in that study were a small group of women with RA from multicase families, who were compared with their unaffected female relatives. As stated in that report the latter group had an unusually and inexplicably low rate of perinatal loss. Nevertheless, it is possible that late reproductive loss is only of importance in those particularly genetically susceptible to RA.

Although sex hormones and pregnancy undoubtedly play a part in the aetiology and pathogenesis of RA, we were unable to confirm the findings of previous studies of increased poor reproductive outcome before disease onset in women with RA. Indeed the results of this study suggest that spontaneous abortions may actually have a 'protective effect' on the development of RA, though further studies are needed before any firm conclusions are reached.

We would like to thank the rheumatological consultants and staff of the following hospitals for their cooperation and help with this of the following hospitals for their cooperation and help with this study: St Bartholomew's Hospital, The London Hospital, Homerton Hospital, Whipps Cross Hospital, Wanstead Hospital and St Andrew's Hospital. We also thank Dr Eve Roman of The London School of Hygiene and Tropical Medicine for access to
data on the population controls and Kathleen Davis for help with the analysis

I Linos A, Worthington J W, O'Fallon W M. Kurland L I The epidemiology of rheumatoid arthritis in Rochester. Minnesota: a study of its incidence, prevalence and mortality. Am f Epidemiol 1980; 111: 87-98.

2 Persellin $\mathrm{R} H$. The effect of pregnancy on rheumatoid arth ritis. Bull Rheum Dis 1977; 27: 922-7.

3 Rudge S R, Kowanko I C, Drury P I. Menstrual crelicity of finger joint size and grip strength in patients with rheumafinger loint size and grip strength in patients with rheu

4 Engel A. Rheumatoid arthritis in US adults 1960-1962. In Bennett P H, Wood P H N, eds. Population studies of the reneumaic diseases. Amsterdam. Excerpta Medica, 1966 rheumatic diseases. Amsterdam: Excerpta Medica, 1966

5 Lawrence J S. Rheumatism in populations. London: Heinemann, 1977.

6 Silman A J. Is pregnancy a risk factor in the causation of heumatoid arthritis? Ann Rheum Dis 1986; 45: 1031-t.

7 Silman A J, Roman E, Beral V, Brown A. Adverse reproduc tive outcomes in women who subsequently develop rheumatoid arthritis. Ann Rheum Dis 1988; 47: 979-81.

8 Kaplan D. Fetal wastage in patients with rheumatoid arthritis. I Rheumatol 1986; 13: 875-7.

9 Tilley B C, Barnes A B, Bergstralh E, et al. A comparison of pregnancy history recall and medical records. Implication for retrospective studies. Am $\mathcal{f}$ Epidemiol 1985; 121 269-8

10 Harlap S, Shiono P H, Ramchanan S. A life table of spontaneous abortions and the effects of age, parity, and other variables. In: Porter I H, Hook E B, eds. Human embryonic and foetal death. London: Academic Press, 1980 145 .

11 Ericson A, Kallen B. An epidemiological study of work with video screens and pregnancy outcome: a case-control study. Am 7 Ind Med 1986; 9: 459-75.

12 Cartright A. Who responds to postal questionnaires? 7 Epidemiol Community Health 1986; 40: 267-73.

13 Kay A, Bach F. Subfertility before and after the development of rheumatoid arthritis in women. Ann Rheum Dis 1965; 24: 169-73. 